\title{
AdEERS Contact
}

National Cancer Institute

\section{Source}

National Cancer Institute. AdEERS Contact. NCI Thesaurus. Code C51797.

A person responsible within the Cooperative Group and/or a particular clinical trial for the completion and filing of reports (along with any supporting documentation) on adverse events to $\mathrm{NCl}$ and FDA via web-based Adverse Event Expedited Reporting System (AdEERS). 